\title{
AMBIENTE DE CONFLUÊNCIA: UM ESTUDO DE CASO NO RIO CAVALO MORTO, AFLUENTE DA MARGEM ESQUERDA DO RIO TELES PIRES NO MUNICÍPIO DE NOVA CANA ̃̃ DO NORTE-MATO GROSSO
}

\author{
Claudete Silveira Damas Machado ${ }^{(a)}$, Fabio Junior do Espirito Santo Andrade ${ }^{\text {(b) }}$, Leila Nalis \\ Paiva da Silva Andrade ${ }^{(c)}$, Marcos dos Santos ${ }^{(d)}$ \\ (a) Acadêmica do curso de Licenciatura em Geografia da Universidade do Estado de Mato Grosso-UNEMAT. \\ Bolsista do Programa Institucional de Bolsas de Iniciação a Docência, Email: klaudete_machadotnn @hotmail.com \\ (b) Acadêmico do curso de Licenciatura em Geografia da Universidade do Estado de Mato Grosso-UNEMAT. \\ Bolsista do Programa Institucional de Bolsas de Iniciação a Docência, Email: fabio_jr.andrade@hotmail.com \\ (c) Professsora Assistente da Universidade do Estado de Mato Grosso-UNEMAT, Doutoranda em Ecologia e \\ Recursos Naturais pela Universidade Federal de São Carlos-UFSCar. Coordenadora do Laboratório de Pesquisa e \\ Ensino em Geomorfologia Fluvial "Antonio Christofoletti". Coordenadora de Área do Subprojeto PIBID/ Geografia \\ / Colider - Mato Grosso. Email: leilaandrade@unemat.br \\ ${ }^{\text {(d) }}$ Professor da Universidade do Estado de Mato Grosso-UNEMAT.Curso de Licenciatura em Geografia. Campus \\ "Vale do Teles Pires". Email: mdsantos_23@hotmail.com
}

\section{EIXO: BACIAS HIDROGRÁFICAS E RECURSOS HÍDRICOS: ANÁLISE, PLANEJAMENTO E GESTÃO}

\section{Resumo}

O presente trabalho tem como objetivo quantificar os sedimentos (fundo e suspensão) em ambiente de confluência do rio Cavalo Morto com o rio Teles Pires. Realizou-se trabalho de gabinete com pesquisas em livros, revistas e artigos científicos. O trabalbo de campo ocorreu em período de cheia e foram feitas observações e coleta dos sedimentos para análise. As análises foram feitas no Laboratório de Ensino e Pesquisa em Geomorfologia Fluvial "Antonio Christofoletti" no campus de Colider Mato Grosso. Concluiu-se que a carga de suspensão é relativamente baixa, no entanto, em razão da sua velocidade, o rio Cavalo Morto, afluente do rio Teles Pires, tem grande capacidade de transportar sedimentos arenosos (areia grossa, média e fina) e seixos.

Palavras chave: Ambiente de Confluência. Carga de sedimentos. Recursos Hídricos.

\section{Introdução}

A bacia hidrográfica ou "bacia de drenagem pode ser considerada um sistema aberto, que recebe energia da atuação climática das forças tectônicas e perde energia a partir da saída de água, sedimentos e nutrientes da área da bacia". Devido à dinâmica, os sedimentos e materiais dissolvidos são transportados para um determinado ponto do canal (COELHO NETO, 1998 apud SOUZA, 2013).

As partículas consideradas relativamente grandes e pesadas (areias e cascalhos) são transportadas por arrasto, rolamento ou salto constituindo a carga de fundo. As partículas consideradas leves (silte e argila) são transportadas em suspensão. O transporte fluvial realizado por suspensão, saltação e arrasto 
"degradam a qualidade da água, levando a restrição dos seus usos: domésticos, industrial, recreacional ou mesmo em usinas hidrelétricas, sendo também prejudicial à vida aquática". Enquanto que os sedimentos finos (silte e Argila) podem atuar como agentes transportadores de poluentes, como inseticidas, herbicidas e metais pesados como mercúrio e o chumbo (SUGUIO, 2003 p.346-347; CHRISTOFOLETTI, 1980).

Vários autores utilizam como metodologia o levantamento dos dados, coleta e análise dos sedimentos e quantificação das variáveis hidrodinâmicas, como os trabalhos de Andrade e Souza (2009) em análise batimétrica e transporte de sedimentos na sub-bacia do córrego das Pitas; Barros e Souza (2012) com a avaliação do grau de degradação e impactos associados na bacia hidrográfica do Córrego Sangradouro, Cáceres - MT; Santos et al. (2013) abordam a dinâmica fluvial da bacia hidrográfica do Córrego Cachoeirinha no município de Cáceres MT- Brasil, CIMA et al. (2014) analisaram a frequência granulométrica e deposição de sedimentos em ambientes do corredor fluvial do rio Paraguai, Pantanal Superior, Mato Grosso.

O rio Cavalo Morto apresenta canal meandrante e sua sinuosidade favorece os processos erosivos onde ocorrem escavação na margem côncava e deposição na margem convexa . Desta forma, o trabalho teve como objetivo quantificar a carga de sedimentos (fundo e suspensão) transportada em ambiente de confluência com o rio Teles Pires no município de Nova Canaã do Norte/Mato Grosso.

\section{Metodologia}

Realizou-se a revisão da literatura referente à temática em livros, artigos científicos e dentre outros documentos. Para caracterizar os fatores geoambientais (geologia, geomorfologia, solo, e vegetação) utilizou-se os dados disponibilizados em Camargo (2011).

O campo ocorreu no dia 20 de janeiro de 2017. Os sedimentos de fundo foram coletados com o amostrador de mandíbulas e as amostras foram condicionadas em sacolas plásticas de $1 \mathrm{~kg}$. Para a coleta da carga suspensa foi utilizada a técnica empregada por Bülher (2011), onde enxaguou as garrafas plásticas de $1 \mathrm{~L}$ duas vezes com a água do próprio rio e as amostras foram coletadas a $20 \mathrm{~cm}$ da lamina d'água e posteriormente armazenadas em caixa térmica com gelo. Para o fracionamento do material foram realizados em laboratório os ensaios de pipetagem (silte e argila) e peneiramento (areia grossa, areia média e areia fina) (SUGUIO, 1973; EMBRAPA, 1997).

As amostras de sedimento de fundo e suspensão foram analisadas no Laboratório de Pesquisa e Ensino em Geomorfologia Fluvial "Antonio Christofoletti” da Universidade do Estado de Mato Grosso Campus de Colíder. Para calcular a área na seção transversal foi adotada a fórmula: A= LxP (CUNHA, 1996). Onde: 
$\mathrm{A}=$ Área da seção; $\mathrm{L}=$ Largura do canal; $\mathrm{P}=$ Profundidade média. Para obter o cálculo da vazão foi utilizada a seguinte fórmula: $\mathrm{Q}=\mathrm{VxA}$ (CUNHA, 1996). Onde: $\mathrm{Q}=$ Vazão; V = Velocidade das águas; $\mathrm{A}$ = Área.

\section{Resultado e discusão}

A área de estudo compreende o baixo curso do rio Cavalo Morto, afluente do rio Teles Pires no município de Nova Canaã do Norte. A confluência do rio Cavalo Morto com o rio Teles Pires está situada nas cordenadas $10^{\circ} 50^{\prime} 44^{\prime}$ 'S e $55^{\circ} 54^{\prime} 22.3^{\prime \prime} \mathrm{W}$. A vegetação das margens (direita e esquerda) do baixo curso do rio corresponde em geral a formações florestais que se alternam, em função das características do substrato, com elementos ombrófilos predominando em solos profundos e úmidos, próximos às linhas de drenagem. Apresenta formações, com porte elevado, entre 20 a $30 \mathrm{~m}$ de altura e emergentes de até $35 \mathrm{~m}$, apresentando-se perenifólia nas porções rebaixadas, enquanto que nos relevos residuais assumem feição fortemente decídua (CAMARGO, 2011).

Quanto à geologia que compreende a área de estudo, pertence ao Grupo Iriri: riólitos, riodacitos, andesitos, basaltos, rochas piroclásticas e ignimbritos granófiros, riebeckita granitos e granitos rapakivi. (rd-riodacitos) do Complexo Xingu. Situa-se na planície fluvial com área aplanada resultante de acumulação fluvial, periódica ou permanentemente alagada, e, formas dissecadas com topos apresentando morfologias convexas (CAMARGO, 2011).

Ainda conforme Camargo (2011) o solo se apresenta como Latossolo Vermelho-Escuro, distrófico A moderado, textura média, fase Floresta Tropical Subcaducifólia, relevo plano e suave ondulado; Areias Quartzosas, distróficas e álicas A moderado, fase Floresta e Cerradão Tropical Subcaducifólios, relevo plano e suave ondulado; Latossolo Vermelho-Amarelo distrófico A moderado textura média fase Floresta e Cerradão Tropical Subcaducifólios relevo plano e suave ondulado; Podzólico Vermelho-Amarelo distrófico Tb A moderado textura média/argilosa fase Floresta Equatorial subcaducifólia relevo suave ondulado, ondulado e forte ondulado; Solos Litólicos distróficos A moderado, textura média, fase Floresta Equatorial Subcaducifólia, relevo forte ondulado e ondulado, substrato rochas granítico-gnáissicas; Latossolo Vermelho-Amarelo distrófico A moderado, textura argilosa, fase Floresta Equatorial Subcaducifólia, relevo suave ondulado; Solos Concrecionários Latossólicos, distróficos A moderado, textura média, fase Floresta Equatorial Subcaducifólia, relevo suave ondulado e ondulado.

O rio Cavalo Morto apresenta área transversal de $67.63 \mathrm{~m}^{2} \mathrm{com}$ profundidade média de $2.83 \mathrm{~m}$, a largura de $23.9 \mathrm{~m}$. Nessa seção a vazão registrou $10.89 \mathrm{~m} 3 / \mathrm{s}$. Enquanto que a montante da confluêcia o rio Teles Pires apresentou seção de $1.089 .836 \mathrm{~m}^{2}$, e $978.818 \mathrm{~m}^{2}$ de área a jusante, dados respectivos à foz do 
afluente. Os dados demonstram que o ambiente de confluência possui área, velocidade e vazão consideradas (Tabela I).

TABELA I-Variáveis Hidrodinâmicas

\begin{tabular}{|c|c|c|c|c|c|}
\hline \multirow{2}{*}{ Ponto } & \multicolumn{5}{|c|}{ Perfil Transversal } \\
\hline & Largura (m) & Profundidade (m) & Velocidade $(\mathrm{m} / \mathrm{s})$ & Área $\left(\mathrm{m}^{2}\right)$ & $\operatorname{Vazão}\left(\mathrm{m}^{3} / \mathrm{s}\right)$ \\
\hline A - Montante rio Teles Pires & 320,54 & 3.4 & 0,01 & $1.089,836$ & 10,89 \\
\hline B - (Afluente) & 23,90 & 2.83 & 0,01 & 67.63 & 0,67 \\
\hline C - Jusante rio Teles Pires & 314,78 & 3.1 & 0,01 & 978.818 & 9,75 \\
\hline
\end{tabular}

O ponto (A) a montante do rio Teles Pires, apresenta afloramento rochoso, sendo coletados seixos (medida $47 \mathrm{~mm} / 43 \mathrm{~mm} / 51 \mathrm{~mm}$ ) e $0,008 \mathrm{mg} / \mathrm{L}$ de carga suspensa. Com relação aos sedimentos de fundo verificou-se que o rio Cavalo Morto tem capacidade de transportar sedimentos arenosos (frações maiores). De acordo com Christofoletti (1980) e Embrapa (2007), as partículas de granulometria maior podem ser classificadas em: areias, casalho e calhau. Na margem direita esse transporte está sendo ocasionado devido a processos erosivos (margem côncava), notando-se essa deposição na margem esquerda (margem convexa). Ponto (B) no afluente registrou grande quantidade de sedimentos de fundo, sendo este em grande parte de areia fina seguido de areia média, areia grossa, argila e silte, bem como seixos. Um dos fatores que contribuem para o transporte da carga é a velocidade considerada do canal (Tabela II).

TABELA II - Sedimentos de Fundo e Suspensão. * Margem Direita e Margem esquerda

\begin{tabular}{|c|c|c|c|c|c|c|c|c|c|c|c|}
\hline \multirow[t]{2}{*}{ Ponto } & \multicolumn{10}{|c|}{ Sedimento de Fundo (\%) } & \multirow{2}{*}{$\begin{array}{c}\text { Sedimento em } \\
\text { Suspensão } \\
(\mathrm{mg} / \mathrm{L})\end{array}$} \\
\hline & \multicolumn{2}{|c|}{ Areia Grossa } & \multicolumn{2}{|c|}{ Areia Média } & \multicolumn{2}{|c|}{ Areia Fina } & \multicolumn{2}{|c|}{ Silte } & \multicolumn{2}{|c|}{ Argila } & \\
\hline $\begin{array}{l}\text { A - (Montante rio } \\
\text { Teles pires) }\end{array}$ & \multicolumn{2}{|c|}{---- } & \multicolumn{2}{|c|}{---} & \multicolumn{2}{|c|}{--- } & \multicolumn{2}{|c|}{--- } & \multicolumn{2}{|c|}{--- } & 0.008 \\
\hline \multirow[t]{2}{*}{ B -(Afluente) } & MD* & $\mathrm{ME}^{*}$ & MD & $\mathrm{ME}$ & MD & ME & MD & ME & MD & $\mathrm{ME}$ & \multirow[b]{2}{*}{0.006} \\
\hline & 0.50 & 0.15 & 0.79 & 0.60 & 84.37 & 40.95 & 13.46 & 53.55 & 0.88 & 4.75 & \\
\hline $\begin{array}{l}\text { C-(Jusante rio } \\
\text { Teles Pires) }\end{array}$ & \multicolumn{2}{|c|}{0.25} & \multicolumn{2}{|c|}{4.18} & \multicolumn{2}{|c|}{95.21} & \multicolumn{2}{|c|}{0.07} & \multicolumn{2}{|c|}{0.29} & 0.005 \\
\hline
\end{tabular}

De acordo com Giannini e Melo (2009) em sua tabela sobre intervalos granulométricos os mesmos classificam um fragmentos de rocha coletados no ponto central do canal como bloco ou calhau (116 mm) e o outro com medida de $14 \mathrm{~mm}$ como seixo .

Enquanto que a jusante do rio ponto (C) foi registrado $95.21 \%$ de areia fina. O aparecimento da carga de fundo está relacionado à descarga detrítica no ambiente de confluência com o rio Cavalo Morto. Com esses dados afirma-se que esse afluente do rio Teles Pires tem competência para transportar sedimentos arenosos (Tabela II). 


\section{Considerações finais}

A confluência do rio Cavalo Morto encontra-se na margem esquerda do rio Teles Pires, a jusante da Usina Hidrelétrica de Colider. Os dados demonstraram que o rio tem capacidade de transportar sedimentos arenosos (grossa, média e fina do fundo do canal). Á área apresenta erosão marginal contribuindo assim com o aumento da carga detrítica do ambiente de confluência com o rio Teles Pires.

\section{Bibliografia}

ANDRADE, L. N. P. S.; SOUZA, C. A. de. Sub-bacia hidrográfica do Córrego das Pitas: análise batimétrica e transporte de sedimentos. Geociências. São Paulo: UNESP, v. 28, n. 4, p. 387-400, 2009. Disponível em: <http://www.revistageociencias.com.br/28_4/Art\%2004_Andrade.pdf> Acesso em: 05 de jan. de 2017.

BARROS, L. R.; SOUZA, C. A. de. Avaliação do grau de degradação e impactos associados na bacia hidrográfica do Córrego Sangradouro, Cáceres - MT. Revista Eletrônica da Associação dos Geógrafos Brasileiros. Seção Três Lagoas/MS $\quad-\quad \mathrm{n}^{\circ} 16 \quad-\quad$ Ano 9 , Novembro 2012. Disponível em: <http://seer.ufms.br/index.php/RevAGB/article/view/598> Acesso em: 05 de jan. de 2017.

BÜHLER, B. F. Qualidade da água e aspectos sedimentares da bacia Hidrográfica de rio Paraguai no trecho situado entre a baía do Iate e a região do Sadão, município de Cáceres (MT) sob os enfoques quantitativos e perceptivos. 2011, 141 f. Dissertação (Mestrado em Ciências Ambientais) Universidade do Estado de Mato Grosso, Cáceres, 2011. Disponível em: acesso em: 05 de jan. de 2017.

CAMARGO, L. (org.). Atlas de Mato Grosso: Abordagem socioeconômica-ecológica. Cuiabá, MT: Entrelinhas, 2011.

CARVALHO, N. de O..Hidrossedimentologia Prática. Rio de Janeiro: CPRM, 1994. 372 p.

CIMA, E. F.; ANDRADE, L. N. P. da S.; SOUZA, C. A. de; SANTOS, M. dos; LEANDRO, G. R. dos S..Frequência granulométrica e deposição de sedimentos em ambientes do corredor fluvial do rio Paraguai, pantanal superior, Mato Grosso. Cadernos de Geociências. v. 11, n. 1-2, nov. 2014 . Disponível em: <https://portalseer.ufba.br/index.php/cadgeoc/article/view/9769/8833> acesso 05 de jan. de 2017.

CUNHA, S. B. Geomorfologia Fluvial. In: Cunha S. B. e Guerra. A. J. T. (orgs.). Geomorfologia: Exercícios, técnicas e aplicações. Rio de Janeiro: Bertrand Brasil, 1996.

CHRISTOFOLETTI, A.. Geomorfologia. São Paulo: Edgard Blücher, 1980.

EMBRAPA. Manual de Métodos de Análises de Solo. 2. ed. Rio de Janeiro: Embrapa Solo. 1997. 212 p.

EMBRAPA. Manual Técnico de Pedologia. 2. ed. Rio de Janeiro: Embrapa Solo. 2007. 316 p.

GIANNINI, P. C. F.; MELO, M. S.de; Do Grão à rocha sedimentar: erosão,deposição e diagenese. In: TEIXEIRA, W.; FAIRCHILD, T. R.; TOLEDO, M. C. M. de; TAIOLI, F.(orgs.). Decifrando a Terra. São Paulo: Nacional, 2009.

SANTOS, M. dos; SOUZA, C. A. de; SOUSA, J. B. de; FILHO, A. R.; SANTOS, R. P. dos. A dinâmica fluvial da bacia hidrográfica do Córrego Cachoeirinha no município de Cáceres MT- Brasil. Enciclopédia Biosfera, Centro Científico Conhecer. Goiânia, v.9, n.17; p.3160 2013. Disponível em: <http://www.conhecer.org.br/enciclop/2013b/MULTIDISCIPLINAR/A\%20DINAMICA\%20FLUVIAL.pdf> Acesso em: 05 de jan. de 2017.

SOUZA, J. O. P. de. Dos sistemas ambientais ao sistema fluvial - uma revisão de conceitos. Caminhos da Geografia. Uberlândia v. 14, n. 46 Set/2013 p. 224-233. Disponível em: < http://www.seer.ufu.br/index.php/caminhosdegeografia/article/view/22281/13241> acesso em: 06 de jan. de 2017. 


\begin{tabular}{|c|c|}
\hline $\begin{array}{l}\text { XVII Simpósio Brasileiro } \\
\text { de Geografia Fisica Aplicada }\end{array}$ & OS DESAFIOS DA GEOGRAFIA FÍSICA NA FRONTEIRA DO CONHECIMENTO \\
\hline $\begin{array}{l}\text { I Congresso Nacional } \\
\text { de Geografia Física }\end{array}$ & $\begin{array}{l}\text { Campinas - SP } \\
28 \text { de Junho à } 02 \text { de Julho de } 2017\end{array}$ \\
\hline
\end{tabular}

SUGUIO, K.. Geologia Sedimentar Aplicada. São Paulo: Edgard Blücher, 2003. p.346-347.

SUGUIO, K. Introdução a sedimentologia. São Paulo: Edgard Blücher, 1973.

\section{Agradecimentos}

A concessão de bolsa PIBID/Capes; E auxilio financeiro da/ FAPEMAT/UNEMAT) 